\title{
Empoderamento de usuários finais no desenvolvimento de ambientes virtuais de participação social
}

\author{
Thiago A. M. Silva ${ }^{1}$, Sean Siqueira ${ }^{1}$, Renata Araujo ${ }^{2}$ \\ ${ }^{1}$ Programa de Pós-graduação em Informática - Universidade Federal do Estado do Rio \\ de Janeiro (UNIRIO) \\ Avenida Pasteur 458, Urca - Rio de Janeiro, RJ - Brasil \\ ${ }^{2}$ Faculdade de Computação e Informática - Universidade Presbiteriana Mackenzie \\ Rua da Consolação, 930, Consolação - São Paulo, SP - Brasil \\ \{thiago.marques, sean\}@uniriotec.br, renata.araujo@mackenzie.br
}

\begin{abstract}
This article introduces a proposal that enables end users, with no knowledge in software development, to create prototypes in institutional Virtual Environments of Social Participation. Then, the proposal aims to empower end-users in the practice of innovation in institutions.
\end{abstract}

Resumo. Este artigo introduz uma proposta que habilita usuários finais, sem conhecimento em desenvolvimento de softwares, a criarem protótipos de Ambientes Virtuais de Participação Social institucionais. Assim, a proposta visa empoderar usuários finais na prática da inovação nas instituições.

\section{Introdução}

Com a difusão das Tecnologias de Informação e Comunicação (TIC), a administração pública brasileira sofreu pressões de uma sociedade que exige melhoria da máquina pública. Assim, o governo precisa repensar suas estratégias, e entregar serviços que atendam às necessidades do público e empoderem os cidadãos [Barbosa 2018].

Uma resposta do governo às pressões foi incentivar o uso das TIC na administração pública. Mas o governo nem sempre pode monitorar a execução de serviços na perspectiva dos cidadãos e atender às suas necessidades específicas, gerando desconfiança nos serviços ofertados, e indiferença à prática da democracia, distanciando os provedores de serviços dos usuários [Lopes et al. 2018] [Diirr et al. 2018].

Para ter a confiança dos cidadãos, os governos devem se preparar para a colaboração cidadã com a co-produção e captação de ideias [Lopes et al. 2018]. Através das TIC, deve-se facilitar a participação cidadã nas administrações e serviços públicos.

\section{Apresentação do Problema}

Um meio de cooperação entre cidadãos e entes públicos é o citizensourcing, que é quando uma tarefa exercida por agente público é exercida por outras pessoas através de uma chamada aberta. São ofertadas interações de criação de valor público e co-criação dos cidadãos, integrando atores externos em processos governamentais. Assim, cidadãos ajudam nos desafios da administração pública [Hilgers e Ihl 2010].

Uma prática de inovação aberta e, portanto, de citizensourcing é o hackathon, que é uma maratona para desenvolver sistemas em pouco tempo, onde especialistas em 
programação e pessoas sem conhecimento em desenvolvimento de softwares colaboram na criação de propostas para atacar um problema [Briscoe e Mulligan 2014].

Pessoas não profissionais da área das TIC tendem a ter baixo engajamento nestes eventos, pois creem não estarem aptas a cooperar na concepção e criação das soluções tecnológicas por não terem as habilidades necessárias [Silva 2017] [Zapico et al. 2013].

A falta da participação dos não desenvolvedores limita a interdisciplinaridade e inovação, essenciais nas soluções aos desafios que se mostram. Assim, a prática do citizensourcing pode ficar limitada, sem pluralidade de perfis entre os participantes.

A baixa participação social implica: decisões institucionais sem o envolvimento cidadão; na sobrecarga da administração responsável pelas ações e decisões; em ideias não fomentadas pela comunidade; em ações institucionais individuais e não coletivas.

Os não especialistas em TIC devem ter uma alternativa que lhes deem uma autonomia e confiança para criar soluções adequadas aos seus anseios. É objetivo da pesquisa empoderar usuários finais sem formação em desenvolvimento de softwares, para criarem seus Ambientes Virtuais de Participação Social (AVPS).

Para Oliveira e Oliveira (2016) empoderamento é uma ferramenta para atores sociais engajarem na participação democrática. Baquero (2012) expõe empoderamento como ganho de conhecimento e controle sobre forças pessoais, para melhorar sua situação de vida. Aqui assumimos empoderamento como um processo onde indivíduos são estimulados a se conscientizarem de que podem promover mudanças positivas onde vivem, usando meios que os habilitem a criar softwares que apoiem essa mudança.

Instituído em 2014 pela Política Nacional de Participação Social ${ }^{1}$, um AVPS usa as TIC para o diálogo entre administração pública federal e sociedade civil. O AVPS permite a participação social, incluindo de sistemas com poucos meios de interação, até sistemas com mecanismos que permitam o debate de ideias, a elaboração e a publicação dos produtos gerados, como projeto de lei e diretrizes de políticas públicas [Silva 2017].

Um trabalho relacionado é o de Przeybilovicz (2019), que ao abordar governança pública e uso das TIC nas iniciativas de cidade inteligente e redes de interações sóciotécnicos, também identificou que a rede de cooperação estudada foi limitada em termos de alcance ao público em geral, pois ela demonstrou-se restrita às pessoas com habilidades tecnológicas, não chegando a empoderar os demais cidadãos para participar dos projetos, demonstrando ser essa uma grande dificuldade.

\section{Proposta de Solução}

A intenção é incluir participantes não programadores em processos de desenvolvimento aberto de sistemas. Assim, a proposta de solução é identificar diretrizes que apliquem o End-User Development (EUD) em hackathons. E foram identificadas como orientações para serem adotadas: uso de ferramentas EUD; o apoio especializado para orientar participantes sem especialidade em desenvolvimento de softwares; e a propagação de que hackathons são eventos multidisciplinares, e não restritos a especialistas em TIC.

\subsection{Sistematização de Hackathon Universitário com Design Thinking e EUD}

Silva [2017] conduziu uma pesquisa-ação para ampliar a participação social em uma

1 http://www.planalto.gov.br/ccivil_03/_ato2011-2014/2014/decreto/d8243.htm 
instituição pública de ensino através de um hackathon universitário. Nesta pesquisa, foi criado um processo para sistematizar hackathons baseados no Design Thinking (DT).

Evoluímos o processo de Silva [2017] aplicando o EUD para haver a criação de soluções por participantes sem a formação em desenvolvimento de softwares. Definimos ao novo processo as atividades: engajamento, planejamento, imersão, ideação, prototipação e apresentação.

No engajamento são definidas, planejadas e executadas ações para motivar a comunidade, especialmente quem não é desenvolvedor profissional de softwares, a participar do evento. E no planejamento são definidas, planejadas e executadas as ações, conforme as características desejadas, para realizar o evento.

Na imersão se amplia o conhecimento dos participantes sobre os seus objetivos, o seu tema e os cenários-problema relacionados, de forma que se extraiam informações que contribuam na geração de insights que identifiquem oportunidades. E na ideação os participantes propõem soluções tecnológicas a partir do conhecimento advindo das atividades imersivas, do conhecimento explicado, e dos insights gerados.

$\mathrm{Na}$ prototipação é incentivado o desenvolvimento de protótipos tecnológicos para tangibilizar as soluções propostas. Nesse momento os usuários fazem uso de ferramentas de EUD e recebem a orientação de especialistas em programação.

$\mathrm{Na}$ apresentação os participantes apresentam suas ideias em até cinco minutos com a abordagem pitch, e os avaliadores fomentam discussões e apontam sugestões.

\section{Avaliação da Solução}

Com o Método de Extração do Discurso Subjacente (MEDS) [Nicolaci-Da-Costa 2007] são extraídas, dos participantes sem conhecimento em programação, informações qualitativas através de questões como: a motivação em criar soluções úteis à comunidade; como o criador vê que o seu produto beneficia a comunidade; as dificuldades encontradas; e o sentimento de pertencimento e cooperação à comunidade.

\section{Atividades Realizadas}

Em 2018 foi realizado um hackathon na Universidade Federal do Estado do Rio de Janeiro aplicando a proposta presente na seção 3. Nesse evento foi incluído o MIT App Inventor $^{2}$ como ferramenta EUD a ser usada, foi contemplado um material de apoio sobre o MIT App Inventor, e também foi disponibilizado um mentor especializado no MIT App Inventor, para orientar os participantes em como concretizarem as suas ideias.

Essa abordagem permitiu um grupo criar uma solução interessante e funcional pelos jurados e demais participantes do evento.

A atuação do mentor consistiu em explicar o processo de prototipagem, e orientar o grupo a desenhar no papel a sequência de telas para entender as ações realizadas ao apertar botões nas telas. Assim, ao se ver todo o desenvolvimento no papel, pôde-se demonstrar o que fazer no MIT App Inventor.

2 http://appinventor.mit.edu/explore/about-us.html 


\section{Conclusão}

Com o DT e o EUD, propusemos um meio para que não especialistas em TIC sejam mais empoderados em ações colaborativas de criação de inovações em instituições.

Do estudo inicial relatado na seção 5, houve baixa participação de pessoas sem conhecimento de desenvolvimento de software no hackathon. Esta limitação resultou em poucas entrevistas que, apesar das respostas positivas sobre a proposta, não produziu volume de testes suficiente para uma validação científica.

Ainda do estudo apresentado na seção 5, foram analisadas as teorias e técnicas aplicadas, permitindo levantar requisitos e ideias para aprimorar a proposta. Assim, um novo estudo está sendo planejado, considerando os aprimoramentos identificados, e adotado o MEDS para avaliar se o objetivo da pesquisa foi alcançado.

Das melhorias a serem trabalhadas: (i) iniciativas mais elaboradas para promover o engajamento, estimulando a participação de não-desenvolvedores de software; (ii) disponibilização de material e exemplos de uso de ferramentas de EUD antes do evento para que participantes sem o conhecimento de desenvolvimento de software desenvolvam soluções melhores; (iii) trabalhar estratégias mais colaborativas para a maratona e menos competitivas (deseja-se soluções inovadoras desenvolvidas através de um aprendizado com ampla troca de experiências, sem foco em competição).

\section{Referências}

Baquero, R. V. A. (2012) "EMPODERAMENTO: INSTRUMENTO DE EMANCIPAÇÃO SOCIAL? - UMA DISCUSSÃO CONCEITUAL”. Em: Revista Debates, Porto Alegre, v. 6, n. 1, jan.-abr. 2012, p.173-187. ISSN: 1982-5269.

Barbosa, A. F. (2018) Pesquisa sobre o uso das tecnologias de informação e comunicação no setor público brasileiro: TIC governo eletrônico 2017. CGI.BR.

Briscoe, G., Mulligan, C. (2014) “Digital Innovation: The Hackathon Phenomenon”.

Diirr, B., Araujo, R., Cappelli, C. (2018) "Empowering Society Participation in Public Service Processes", em: Strategic Management and Innovative Applications of EGovernment, p.145-175.

Hilgers, D., Ihl, C. (2010) "Citizensourcing: Applying the Concept of Open Innovation to the Public Sector”, em: International Journal of Public Participation, Vol. 4, N. 1.

Lopes, K. M. G., Macadar, M. A., Luciane, E. M. (2018) "VALOR PÚBLICO: O CIDADÃO NO CENTRO DA GESTÃO PÚBLICA", em: Pesquisa sobre o uso das tecnologias de informação e comunicação no setor público brasileiro: TIC governo eletrônico 2017, CGI.BR, p. 75-83.

Nicolaci-Da-Costa, A.M. (2007) "O Campo da Pesquisa Qualitativa e o Método de Explicitação do Discurso Subjacente (MEDS)", Em: Psicologia, Reflexão e Crítica, v.20(1), pp.65-73.

Oliveira, J. R. M., Oliveira, I. M. (2016) "A Democracia participativa sob a ótica do empoderamento e da emancipação", Em: $18^{\text {a }}$ Semana de Pesquisa da Universidade Tiradentes - SEMPESq. ISSN: 1807-2518.

Przeybilovicz, E. (2019) "Governando iniciativas de cidade inteligente: compreendendo os arranjos de governança sócio-técnica e o uso de tecnologias da informação nos 
casos de Curitiba e São Paulo", http://bit.ly/2I3em18 .

Silva, J. (2017) "UMA EXPERIÊNCIA DE DESENVOLVIMENTO ABERTO E COLABORATIVO DE AMBIENTES VIRTUAIS DE PARTICIPAÇÃO SOCIAL NA UNIRIO", http://bit.ly/2VuhWoc .

Zapico, J. L., Pargman, D., Ebner, H., Eriksson, E. (2013) "Hacking sustainability: B

r

o

a

d

e

n

i

$\mathrm{n}$

g

$\mathrm{p}$

a

$r$

$\mathrm{t}$

i

c

i

$\mathrm{p}$

a

$\mathrm{t}$

i

o

n

$\mathrm{h}$

r

o

$\mathrm{u}$

g

h

G

$r$

e

e

n

H

a

c

k

a

$\mathrm{t}$

h

o

$\mathrm{n}$ 